Culture, Health and Sexuality, 2017

http://dx.doi.org/10.1080/13691058.2017.1346200

\title{
From rakhi to romance: negotiating 'acceptable' relationships in co-educational secondary schools in New Delhi, India
}

Padmini lyer

Department of International Development, University of Oxford, Oxford, UK

\begin{abstract}
Based on a multi-method study conducted with middle-class young people (aged 15-17) in three secondary schools in New Delhi, India, this paper focuses on heterosocial dynamics within school peer cultures as an important site of learning about gender and sexuality. Findings indicate that young people negotiate and adapt rakhi (brother-sister) relationships to form less strictly platonic heterosocial friendships, which leave open the possibility of romance. Students' preferences for certain heterosocial relationships are considered within the context of wider cultural narratives. For example, students often rejected rakhi relationships, tied to traditional, conservative values, in favour of heterosocial friendships associated with more modern and desirable social patterns. Moreover, students' own definitions of acceptable heterosocial interactions within peer cultures suggest that they are adept at negotiating norms of gender segregation which are enforced in co-educational schools. In contrast to other formal and informal sources of sexual learning available to them, experiences and stories of romances circulating in schools seemed to offer students alternative, more positive ways of understanding teenage intimacy and sexuality.
\end{abstract}

Keywords: gender, sexuality, friendship, rakhi, secondary schools, India

\section{Introduction}

A considerable body of literature has explored changing patterns of heterosocial dynamics, romance and sexual relationships in India's contemporary youth cultures. As discussed elsewhere (lyer 2017), the past 25 years have seen dramatic shifts in gendered and sexual politics in post-liberalisation, globalised India, particularly for the country's 'new' middle classes (Dasgupta 2014; Nijman 2006). The materialism and consumerism associated with middle-class lifestyles have come to symbolise modernity in India (Nijman 2006), and it has been argued that 'middleclassness' should al so be understood as a 'cultural project or practice rather than a social category or empirical condition' (Liechty 2003). Middleclassness in India has been characterised as an ongoing project of maintaining a 'fine balance' between tradition and modernity, and gendered and sexual moral ities. This links closely to emergent middle-class understandings of how to be 'appropriately Indian' (Iyer 2017; Gilbertson 2014, 121; Donner and De Neve 2011).

This paper explores the dynamics of 'appropriate' gendered and sexual behaviour for middle-class young people within the specificinstitutional context of co-educational secondary schools in New Delhi. As van Wessel (2011) has noted, considering questions of tradition and modernity can perhaps 'seem like a return to tired questions' (2011: 101). However, rather than seeking to define these categories, this paper explores how they are understood, defined and adapted by young people in modern-day India. The terms 'tradition' and 'modernity' can be linked to wider narratives in which Indian culture is defined in relation to specific Hindu practices, and in which Western culture is denounced as a threat to these values and practices, 
particularly in relation to gender and sexuality (Chakraborty 2010; Doniger 2011). Tradition and modernity therefore became a useful frame within the present study in order to understand the way in which students and teachers understood different forms of heterosocial interactions.

Youth cultures in India are largely still characterised by homosociality (Osella and Osella 2006), although platonic, brother-sister relationships provide a context for 'acceptable' heterosocial interactions for unmarried young people (Sancho 2012; Sinha-Kerkhoff 2003; Abraham 2002). Such relationships have traditionally been framed within the context of Raksha Bandhan, a Hindu festival celebrating the relationship between brothers and sisters. As part of this festival, sisters tie rakhi (colourful string bracelets) on their brothers' wrists, symbolising their gratitude for their brothers' protection. The practice of rakhi-tying is not exclusive to family members, however; when celebrating Raksha Bandhan, girls and women also tie rakhi on the wrists of any boys or men from whom they gain or seek protection. Nonsibling rakhirelationships are marked as 'Indian' and safely non-sexual, in a context where premarital sex has traditionally been viewed as unacceptable (Twamley 2013). Sinha-Kerkhoff (2003) and Abraham (2002) suggest that young women and men alike view rakhi relationships favourably, since they provide opportunities for heterosocial interactions in both rural and urban areas.

However, in a context where middle-class young men and women increasingly participate in consumption practices and access new freedoms in spaces such as cinemas, cafés and shopping malls (Dasgupta 2014; Phadke, Khan and Ranade 2011), young people's interactions are far from limited to platonic rakhi relationships (Twamley 2013; Lukose 2009; Osella and Osella 2006; Abraham 2002). Abraham (2002) discusses the prevalence of 'timepass', casual sexual relationships among college students in Mumbai, while Mehra, Savithri and Coutinho (2002) similarly note that unmarried young people in Delhi frequently find opportunities for sexual relationships in spite of the restrictions imposed by families. Among middle-class young people in Hyderabad, Gilbertson (2014) notes that heterosocial friendships and romances have become an important marker of desirable, modern consumer practices, with young women preferring to socialise with and be 'available' to young men rather than being identified as unfashionable, excessively traditional behenjis, or sisters (Gilbertson 2014, 149). At the same time, casual sexual relationships are characterised by gender asymmetry. While permissible and socially valued among young men, young women enter into such relationships at considerable risk to their social reputation (Gilbertson 2014; Mehra, Savithri and Coutinho 2002; Abraham 2002).

While there have been persistent anxieties regarding an increase in young people's sexual activity in post-liberalisation India (Subiaya 2008; Abraham 2002), Uberoi (2011) and Srivastava (2007) have warned against an interpretation of a veil of prudish "silence" around sexuality [...] finally being lifted' over the past 25 years (Uberoi 2011, 277). As discussed in lyer (2017), it seems more accurate to say that the visibility of romantic and sexual relationships within youth culture has increased over this period in India, which has seen feminist and LGBT mobilisation around sex-positive, non-normative sexualities on the left, denunciations of 'unIndian', immoral sexual behaviour from the Hindu right, and the rise of a consumer culture in which new technologies and spaces present the allure of 'Western' modernity.

The present study extends the existing literature by examining heterosocial dynamics within the institutional context of secondary schooling as an important site within which 
middle-class young people learn about gender and sexuality. Based on a multi-method study conducted with Class 11 students (aged 15-17) in three secondary schools in Delhi, findings indicate that young people negotiated and adapted rakhi relationships to form less strictly platonic, more 'modern' heterosocial friendships, which left open the possibility of romance. Students' own definitions of 'appropriate' heterosocial interactions within peer cultures suggest that they were adept at negotiating norms of gender segregation enforced in coeducational schools. As will be discussed, experiences and stories of romances which circulated in the schools also seemed to offer al ternative, more positive ways of understanding teenage sexuality and intimacy.

\section{Methods}

Findings discussed in this paper are based on a multi-method study exploring young people's experiences and understandings of gender and sexuality in secondary schools in New Delhi, India. Fieldwork was conducted from August to December 2013. Three English-medium, coeducational schools were purposively selected for inclusion in the study: a private school, a central government school and a state government school. These schools were included in order to capture the experiences of young people from a range of socio-economic backgrounds. However, while these differences were observed across the school populations (with young people from wealthier backgrounds attending the private school, from largely middle-class backgrounds attending the central government school, and from poorer backgrounds attending the state government school), the young people who volunteered to participate in the later stages of the study were from fairly homogenous backgrounds. This may be due in part to the research being conducted largely in English, which may have encouraged students more confident in their English language skills (typically those from more affluent backgrounds) to volunteer. The study has therefore largely captured the experiences of middle-class, Hindu, upper caste, urban young people; as discussed above, questions of 'middleclassness' (Liechty 2003) therefore became important within the research.

The first stage of the research involved 180 Class 11 students (aged 15-17) completing questionnaires, which focused broadly on students' gendered experiences of schooling and of learning about health at school. Questionnaire respondents were then given the opportunity to volunteer to participate focus groups and individual, semi-structured interviews. 41 students ( 19 girls, 22 boys) participated in both mixed and single-sex focus groups, and 30 of these students (15girls, 15 boys) were then interviewed in dividually. In light of the potentially sensitive topics being discussed, and largely gender-segregated school environments, a male research assistant carried out single-sex focus groups and interviews with the boys. I conducted single-sex focus groups and interviews with the girls, and my research assistant and I co-facilitated mixed focus groups. 25 teachers were interviewed across the three schools, and I also adopted ethnographic methods, which included formal classroom observation, informal interaction with students and teachers, and recording field notes on the experience of living and working in Delhi as a young British-Asian woman.

Within my study, I have adapted Connell's (2000) framework in order to explore the interplay between institutional practices and the forms of agency deployed by students in shaping their experiences of learning about gender and sexuality at school. Following Kehily (2012), Connell (2000), Epstein and Johnson (1998) and others, the study has focused on peer 
cultures as a site in which 'young people [are] active in producing their own identities' in terms of gender and sexuality (Alldred and David 2007: 5). I have also been influenced by Epstein and Johnson's (1998) emphasis on the role of sexual stories in shaping young people's sexual learning, and as discussed in more detail elsewhere, Andrews' (2014) 'political narratives' and Plummer's (1995) 'sexual stories' shaped the narrative analytical framework adopted in my study (lyer 2017). Overall, the idea that gendered and sexual learning takes place through stories, which are themselves located within wider cultural narratives of gender and sexuality, is central to the analytical framework adopted within the study.

The study schools have all been anonymised, and pseudonyms have been adopted for all participants to protect confidentiality; in most cases, student participants chose their own pseudonyms. Ethical approval for this study was granted by the Social Sciences, Arts and Humanities Cross-School Research Ethics Committee at the University of Sussex.

\section{Findings}

\section{Rakhi relationships: institutional and student perspectives}

Many of the teachers who participated in the research emphasised that their co-educational schools were gender-neutral, non-sexual spaces, in which there was no gender-based discrimination, and where girls and boys studied together in 'harmony'. However, it was not the 'togetherness' of girls and boys, but rather the gender segregation within co-educational spaces that was immediately noticeable at the schools. As the research progressed, students and teachers shared numerous accounts of disciplinary practices used to maintain gender segregated spaces:

We should keep an eye on them [...] If the girls or boys they are talking [to each other], we have an eye on them [...] If we find any kind of problem, we immediately point them out. So that they should aware that they should be in their limits, in their behaviour, in their manner. (Garima, female Biology teacher, private school-interview)

At all the schools, students confirmed this kind of intervention from teachers. Akira, a girl at the central government school, complained that the sports teacher had shouted at her for standing with a boy who had been mistakenly assigned monitor duty in the same hallway as her; Aditya, a boy at the private school, noted that some teachers intervened to ensure girls and boys did not sit next to each other in class. These disciplinary practices reflected institutional anxieties specifically related to young people's sexuality. According to many teachers, adolescence was best understood as a 'storm age' during which hormone-fuelled Class 11 students became more interested in romantic infatuations than their education; gender segregation was therefore required in order to keep their burgeoning sexual interest in check, not least because their academic success was at stake. This emphasis on gender segregation also reflected institutional understandings of sexuality exclusively as heterosexuality. Teachers assumed that single-sex groups were 'safely' non-sexual, in contrast to the potentially sexual nature of heterosocial interactions. 
Rakhi relationships proved to be an important exception to the rule of gender segregation, and were idealised as the only acceptable form of heterosocial interactions in coeducational spaces (see Sinha-Kerkhoff 2003; Abraham 2002). Moreover, it was argued that these brother-sister relationships were an essential part of Hindu cultural identity.

In my opinion - say, Raksha Bandhan is there. [...] In actuality, Hinduism is there, Hinduism make[s] some rules and regulations [...] but the thinking of today's generation, [they] are always neglecting [it]. (Suresh, male Commerce teacher, private school-interview)

Raksha Bandhan was celebrated annually at all the schools with extra-curricular activities such as rakhi-making competitions, while rakhi relationships were also celebrated daily at the central government school in the first line of the pledge recited by students in morning assembly: 'India is my country / and all Indians are / my brothers and sisters' (Central Government School Diary 2013-14).

As the Commerce teacher's quotation suggests, rakhi relationships provide certain 'rules and regulations' that determine appropriate forms of interaction between girls and boys at school, and as in the central government school pledge, are even framed as an essential part of Indian national identity. As well as reflecting the pervasive slippage between Hindu practices and Indian-ness (Bénéï 2008), this location of brother-sister relationships within Indian culture creates an emotive, patriotic compulsion for students to form and maintain firmly non-sexual relationships with members of the opposite sex.

Although the Commerce teacher asserted that 'today's generation' are 'always neglecting' Indian traditions such as brother-sister relationships, students at all three schools discussed rakhi relationships. In the following quotation, one of the girls from the private school elaborated on what it meant to have a rakhi brother at school.

I myself have my brother in my school. I mean, he's not my real brother but I just tied the rakhi and he was very much protective and caring to me. [...] So - and whenever something get wrong, any boy just pass the comment [...] he's very much protective, and he comes forward [for] me, [and says] "Say that again what did you say?" [...] Very caring and protective! [laughs] (Leela, female private school student-interview) ${ }^{1}$

Here, Leela emphasises the 'protector' dynamic within brother-sister relationships here, and gives an example of her brother standing up for her, quite literally. Leela draws attention to her brother's physical act of chivalry, as he comes forward and shields her from harm. The potential 'harm' reported here is another boy verbally harassing her ('pass the comment'), but Leela characterises her brother's protection as unconditional. This element of protection within her brother-sister relationship provides a clear echo of the brother-as-protector celebrated during Raksha Bandhan. The idea of brothers 'respecting' their sisters provided an

\footnotetext{
${ }^{1}$ Data originally in Hindi and translated into English are presented in italics, and significant Hindi words are included in brackets.
} 
extension of this idea of protection, with respect defined in quite a specific way:

Um, like [with] eve-teasing, like that. So - [my parents tell us] how should we protest [against] that, and - we should uh, they always tell us [to say] that even the girl, "She is your sister or not?" [...] You should give them respect like you give your sister [...] Like, the manneryou talk to [girls]. If [you] think, someone talks to your sister [like that], then how do you feel? Then - you have to talk them [girls] like that only. (Tornado, male private school student -interview)

Tornado, a vocal advocate of treating girls as siblings, provides an insight into the motivation of boys who step forward to protect their 'sisters'. Tornado reports his parents' advice, to take a stand and discourage other boys from verbally harassing ('eve-teasing') girls by appealing to their assumed sense of duty and protective feelings for their actual sisters.

Tornado, and many other student participants, implicitly defined 'respecting' a girl and sexually harassing her as mutually exclusive. This is uncontroversial enough, but equating 'giving girls respect' with treating girls 'like their sisters' perhaps more problematically suggests that girls can only be respected within a non-sexual relationship. The institutional narrative of brother-sister relationships therefore not only perpetuates regressive gendered power dynamics (in which vulnerable women require protection from their powerful 'brothers'), but also a deeply restrictive conceptualisation of sexuality. Taken to its logical end, the respecting-girls-as-sisters trope frames not just sexual harassment but all male sexual desire as derogatory towards women, and (insofar that female sexuality is imagined at all), characterises women who express sexual desire or agency as unworthy of male respect. As discussed below, many students questioned the assumptions underlying the rakhi paradigm, but these ideas arguably contributed to some of the confusion around how young people could understand sexual desire in positive terms (Iyer 2017).

In contrast to the Commerce teacher's assumption that young people 'these days' neglect ideas about brother-sister relationships, students did draw upon institutionalised, Raksha Bandhan narratives when defining heterosocial peer relationships. Brother-sister relationships also importantly contradicted the official characterisation of education and schools as gender-neutral spaces. Masculinity and femininity are arguably conceptualised as oppositional (and one-dimensional) within the rakhi relationship, while the framing of heterosocial relationships as familial and therefore non-sexual reflects an attempt to control young people's sexuality within co-educational schools. However, in spite of the prominence of rakhi relationships within institutional narratives and peer cultures, many students indicated that they preferred relationships which were less strictly platonic.

\section{Heterosocial friendships}

Although school spaces initially appeared to be largely gender segregated, over time it became apparent that heterosocial peer groups did exist at the schools, and as will be discussed shortly, heterosocial relationships were not only understood within institutional understandings of Raksha Bandhan. One of the girls at the state government school described the various social groups within her class: 
Some girls, they really keep distant from boys, they have their separate groups. But if I talk about my group, we have as much friends in girls as we have in boys [...] I think that is the only group of girls [that] boys respect the most [...] The boys do not like other girls because they are always separate from them. Ah - and some boys are even very separate, they do not talk to girls. Nobody even knows them, except their own classmates. (Rani, female state government school student interview)

Rani characterises three distinct types of peer groups here: the girls who 'are al ways separate' from the boys, the boys who 'do not talk to girls', and groups in which there are 'as [many] friends in girls as [...] in boys'. Rani ranks two of these groups based on her male friends' opinions of them; the boys 'do not like' the girls who are 'always separate from them', while the girls they 'respect the most' are those who socialise with them. Rani locates herself and her girlfriends within the latter group, in which girls are 'friends with boys'. She expresses considerable disdain for the groups of boys who do not mix with girls, suggesting their irrelevance to the school's social scene, and perhaps echoing her male friends' poor opinions of girls who similarly remain 'separate'. This description indicates that school peer cultures included heterosocial friendships as well as gender segregated groups, and, at least according to Rani, membership of a heterosocial group conferred greater social legitimacy at the school.

Moreover, many students questioned the need to frame these heterosocial relationships in terms of Raksha Bandhan. In particular, rakhi relationships were viewed as problematic due to their exclusively platonic undertones.

Ah, in school life, the statement [that boys should treat girls like sisters] is correct. But in college ah, no, this statement is wrong, because if we treated all girls like our sister, then what about our married life? [...] In Hindu[ism], we cannot marry our sisters, so, if we make all the girls our sister so [...] who the boys will marry? (Akash, male central government school student -interview)

Akash does not reject rakhi relationships entirely, suggesting these relationships are appropriate at his current age, but not beyond. He problematises the non-sexual nature of rakhirelationships by pointing to their incestuous implications, and Keshar, one of the boys at the private school, made a similar argument by asking 'how will the world go, more' (i.e. how will people reproduce) if girls and boys only form rakhi relationships. Interestingly, my research assistant did not explicitly ask the boys if they thought all girls should be treated as sisters; Akash and Keshar seem to have assumed this themselves when answering, or alternatively, they may have deliberately used hyperbole to characterise rakhi relationships as absurd.

The platonic undertones of the rakhi relationship also meant that being labelled as a 'brother' or a 'sister' could be viewed as socially undesirable.

[Author]: [...] So in general, do you think girls and boys treat each other like brother and sister in your school?

Sweety: No! 
[Author]: No? [laughs]

Sweety: Not at all! [laughs] By mistake, any-ah, [if] any girl said any boy [is a] brother - they said, "Whose brother?!" [laughs] Actually no boy like that a girl call him brother.

(Sweety, female private school student-interview)

One of the guys proposed to a girl. He said, "I like you", and she said, "I think of you as a brother (bhai)" [laughs]

(Jonny, male state government school student-interview)

Sweety's response suggested that she found the idea of students forming rakhi relationships somewhat absurd, while Jonny's brief story provides a potential explanation for Sweety's assertion that none of the boys like to be seen as brothers. In Jonny's story, a girl rejects a boy's romantic proposal by saying that she thinks of him as a brother - perhaps the equivalent of relegating him to the friend zone. Interestingly, Jonny uses the English words 'propose' and 'like' when characterising the boy's romanticintentions, and the Hindi word bhai when voicing the girl's deflection of the proposition. These linguistic shifts subtly point to the middle-class balancing acts discussed by lyer (2017), Gilbertson (2014) and Donner and De Neve (2011), underlining a difference between the 'Indian-ness' of the implied rakhi relationship, and 'Western' notions of 'proposing', 'liking' (being attracted to) someone, and wanting to form a girlfriend-boyfriend relationship.

As discussed above, some students clearly did value their own brother-sister relationships, but on the whole, students cast rakhirelationships as either rare or undesirable. Instead, many students described 'friendship' between girls and boys as the preferred form of heterosocial relationship.

You shouldn't treat everyone like a sister (behen) - I mean, everyone in our class should be friends. Not like a sister, and not like a girlfriend either. You can't treat everyone like a sister, it wouldn't be right (achha bhi nahin lagega). To live in the present (aajke zamaane) you can't treat everyone like sisters. If you think someone's a friend then treat them like a friend and don't cross the limit (had). (Harsha, female central government school student-interview)

Harsha describes three ways in which heterosocial relationships can be classified: as (brother)sister, friends, or (boyfriend-)girlfriend. Her assertion that boys should not treat all girls as sisters echoes arguments made by Akash, but Harsha provides an alternative justification. She suggests that brother-sister relationships are old-fashioned and no longer relevant in the present (aajke zamaane, literally 'today's time'); this also seems to be reflected in her use of the Hindi word for sister, behen, in comparison to the English words 'friend' and 'girlfriend'. Again, these linguistic distinctions potentially characterise Indian, bhai-behen relationships as out-of-date, compared to more contemporary, Westernised friendships and girlfriendboyfriend relationships.

Importantly, Harsha defines friendship as a distinct category from rakhi relationships and romantic relationships. Other students offered explanations for what the difference between a brother-sister relationship and a heterosocial friendship might be; Abby, one of the 
boys at the state government school, characterised heterosocial friendships as less restrictive than rakhi relationships. He indicated that boys could not talk about 'girlfriends and all', nor could they express attraction to other girls in front of their rakhi sisters. This suggests that treating a girl like a sister not only precludes being sexually attracted to her, but also requires a sense of decorum that prohibits discussion of anything sexual. Without these brother-asprotector requirements, Abby suggested that a heterosocial friendship can be a more equal and emotionally closer relationship.

While students characterised heterosocial friendships as more relaxed, equal and modern than brother-sister relationships, friendships were importantly still marked as platonic relationships. However, a further distinction seemed to be that, unlike rakhi relationships, heterosocial friendships were not seen as permanently platonic.

You know what, until $10^{\text {th }}$ [Class] I used to tie rakhi on [my brother's] hand, on his wrist, but now, in 11th - he said, "Sweety, now no more rakhi - I'm your friend!" [laughs] I said, "Rakhi?" - he said, "No!" [laughs] So - now I don't have any brother in school, I only have friends. (Sweety, female private school student interview)

Sweety's story provides an example of the ways in which students negotiated and played with variously defined heterosocial relationships. By informing Sweety that she should not tie rakhi on his wrist in Class 11, her rakhi brother indicates that he wants to be 'friends' with her instead. The timing of this change also seems important; while a firmly platonic relationship may have been appropriate at age 15 in Class 10, it is apparently no longer fit for purpose at age 16 in Class 11.

The undesirably platonic nature of rakhirelationships also seemed to have currency in wider popular culture, as I learned while watching an epis ode of Jhalak Dikhla Jha (the Indian version of Strictly Come Dancing) in my hostel. During a skit on the show, a glamorous Bollywood actress told the two male hosts that she had a surprise for them. The first host closed his eyes and leaned forward in anticipation; the actress leaned in, held his hand, and tied a rakhi bracelet on his wrist. He howled in mock-horror as he realised what had happened, while the second host quickly ran to the back of the stage to avoid a similar fate. The rakhitying and the first host's crestfallen reaction provoked a roar of laughter from the studio audience and my viewing companions in the hostel, suggesting a shared appreciation for his unfortunate relegation to a clearly undesirable, non-sexual relationship with the actress (Field notes, 06.09.13).

This skit, along with Sweety's quotation and similar stories from other students, suggested that rakhirelationships could be located within an alternative narrative. As well as being glorified as a nationalistic celebration of men as the brave protectors of women (as in the more 'official' images of Raksha Bandhan discussed above), rakhi relationships could also be suggestively undermined in order to express romantic interest. Within school peer cultures, the rejection of a rakhi bracelet, and therefore the sibling undertones of Raksha Bandhan, therefore seemed to provide a useful way of transitioning to a less strictly platonic heterosocial friendship within student peer cultures.

Overall, students' critiques and rejection of rakhi relationships, which were sanctioned by school and wider cultural narratives, reflect the ways in which they actively engaged with 
and subverted attempts to control potential expressions of their sexuality. These findings also indicate more complex heterosocial dynamics within youth cultures than those outlined by Abraham (2002), whose conceptualisation of bhai-behen relationships does not point to distinctions between rakhirelationships and heterosocial friendships. Stories told by students in the present study suggest that they played with expected boundaries and formed heterosocial friendships which were highly valued within peer cultures (see also Gilbertson 2014). Findings discussed here are also reminiscent of Ke hily and Nayak's (1996) description of sexuality as a site where 'boundaries may be created by the school and tested by the pupils', and as a 'playground within which humour is used and power struggled over' $(1996,214)$. Overall, students' preferences for less restrictive heterosocial friendships suggest that they did not feel their interactions with the opposite sex had to be defined within the 'safe' confines of brother-sister relationships. Moreover, as discussed in the following section, the preference for friendships over rakhi relationships can be linked to the high social value placed upon peer romances by students.

\section{Peer romances - defining (and circumventing) physical 'limits'}

In spite of institutional efforts to keep heterosocial relationships strictly platonic, students and teachers described 'girlfriend-boyfriend' relationships as commonplace at all the schools. Moreover, it seemed that these romances were an important source of sexual learning within peer cultures, whether or not students were actively involved in such relationships. Students' (mostly) non-physical girlfriend-boyfriend relationships are referred to here as 'romantic' relationships, as distinct from the sexual relationships described later on.

The majority of students who participated in the research emphasised that girlfriend-boyfriend relationships were fine, as long as the couple remained within their 'limits'. At the central government school, Akira provided an example of how these limits worked within her own relationship:

See, I'm in a relationship from the past three years. My boyfriend's good, he never does any such [sexual] things [...] We just hug each other, that's it. He used to kiss me on my cheeks, that's it. That's a physical relationship in my relationship, you know. This much is good but, you know - um, ah - more physical relationship is bad for us in this age. Seriously. (Akira, female central government school student - interview)

Akira describes physical intimacy beyond hugging and kissing as inappropriate at her age, and many students (both those in relationships and those who were single) similarly described the importance of imposing such limits while at school. Of course, students may have further emphasised these physical limits within research encounters based on what they felt to be 'tell-able' when talking to an adult (Plummer 1995). In this account of her relationship, at least, Akira praises her boyfriend of three years for not initiating further sexual intimacy, and other couples were similarly celebrated for the physical limits within their relationships. Mala, one of the girls at the state government school, described a 'perfect couple' who were loved by all the students in her school; according to Mala, the reported near-worship of this couple 
importantly hinged on their purely 'emotional bond', which she emphasised was far superior to a mere 'physical bond'. Several boys also emphasised the importance of imposing physical limits within appropriate girlfriend-boyfriend relationships, echoing non-physical 'true love' relationships described by Abraham (2002) and Gilbertson (2014). Overall, as a source of sexual learning, stories about such couples seemed to encourage students in school to aspire to similarly idealised, romantic relationships by imposing physical limits with their partners. However, in addition to stories of purely romantic love, stories of students' sexual activity also circulated in the schools.

\begin{abstract}
I heard that -students in Class 12, one called Dimple and one called Gaurav. They were like brother-sister (bhai-behen) in school. But they went out together - I mean, they booked a room in a hotel - and there, whatever happened - I don't know what. But there was a boy from our school, so he saw them when they came back, and he told us - like, "They went to the hotel, booked a room and a lot has happened between them". (Harsha, female central government school student-interview)
\end{abstract}

Several students at the central and state government schools told a similar-perhaps the same - story about a student couple who booked a hotel room and (implicitly) had sex. I was intrigued by the repetition of these stories across the two schools, and wondered if perhaps this was something of an urban legend, or a trope of teenage sexual rebellion. However, the telling of these stories is perhaps of more interest than the veracity of their claims. In this case, Harsha suggests that the couple used a rakhi relationship while in school to conceal their actual girlfriend-boyfriend relationship - further suggesting how adept students were at playing with notions of 'acceptable' heterosocial interactions, and consistent with previous findings from Sinha-Kerkhoff (2003) and Abraham (2002). Notably, even when recounting the events at the heart of the story, Harsha avoids directly stating what the couple got up to in their hotel room; her choice of language suggests tension between what is implicitly tell-able and explicitly unsayable within sexual stories (Plummer 1995).

While some stories about students' sexual experiences were told at all the schools, sexual activity among students did not seem to be particularly common. Romantic relationships seemed to have higher social value if they stayed within broad peer definitions of 'acceptable' limits, with physical intimacy restricted to hugging and kissing. Confirming findings from Twamley (2013) and Abraham (2002), who have discussed the value of non-sexual romantic relationships within Indian youth cultures, it seemed that sexual activity among student couples was the exception rather than the norm. This may reflect middle-class norms of pre-marital purity (Parry 2001), or alternatively, may be due to the younger age range of participants in this study (who were mostly 16 years old). Nevertheless, even if most couples did not go quite as far as booking hotel rooms, there were numerous stories of students seeking out clandestine spaces (including empty classrooms and concealed spaces behind school buildings) to explore acceptable forms of physical intimacy, which suggested alternative experiences and understandings of 'risk' within peer romances. 
Certain spaces beyond school also offered opportunities for peer romances to blossom more openly. The majority of students who participated in the research revealed that they attended tuition classes or coaching centres frequently². Kumar (2011) and Sancho (2012) have characterised coaching centres as emblematic of middle-class pressures to achieve academic and career success, and I also initially understood students' coaching centre attendance as further proof of the academic pressures weighing down on them. However, coaching centres were also a significant space for less academic aspects of peer cultures.

Like, I'm in an institute, there it's also huge [for] couples. Only, I mean, on the second flooryou'll find couples, I mean that place is packed with all the couples in Delhi! (Rocco, male state government school student -interview)

Rocco was one of several students who mentioned that young people frequently paired off at coaching centres. His claim that 'all the couples in Delhi' are to be found on the second floor of his institute evocatively suggests that young people from all over the city flock to coaching centres (and apparently his in particular) in search of romance. Rocco said that he himself had not found a girlfriend at his institute, indicating that romances were not a guaranteed feature of after-school classes. However, this collision of extra study and potential romance is intriguing; students' presence at coaching centres ostensibly reflects the urban, middle-class pursuit of academic and career success, and yet these centres also offer a legitimate, unsupervised space in which heterosocial peer cultures (and therefore romances) can flourish. As Kehily (2012) has argued, in the context of 'increased regulation of school life through testing, monitoring and processes of individualisation', sexual cultures within (and beyond) schools become important to young people as 'autonomous, peer-generated sites of resistance, providing adult-free and education-free zones in which students can negotiate what is acceptable, desirable and what is "too much"' (2012, 263-4). While coaching centres are not exactly 'adult-free' or 'education-free', the absence of adults who regulate young people's behaviour - school teachers and parents - meant the absence of pressures to perform both academically and 'appropriately' within heterosocial peer cultures (lyer 2017).

Risk-based narratives of sexuality which dominated school and media sources of sexual learning had some influence within peer cultures; this was particularly apparent in the definition of 'acceptable' relationships as mostly non-physical, and definitely not involving sex. Within heterosexual limits, students willingly risked institutional and parental censure by seeking out liminal spaces in school and beyond in order to pursue romantic relationships. These risks not only translated into considerable prestige among peer groups, but also offered positive understandings of teenage sexuality. Pursuing romantic relationships also provided young people with a means of further undermining norms of gender segregation and platonic ideals of rakhi relationships. While actual sexual relationships were not necessarily sanctioned within peercultures, peer romances meant that students could explore and understand ideas of intimacy and desire in much more positive terms than the risk-based narratives of sexuality that dominated their formal and informal sources of sexual learning.

\footnotetext{
$273.0 \%$ of students $(n=119)$ stated that they attended tuition 'sometimes' or 'all the time' $(\mathrm{N}=163)$.
} 


\section{Discussion}

Findings discussed in this paper indicate that heterosocial dynamics within school peer cultures formed an important site within which young people negotiated specific understandings of tradition and modernity. Going beyond previous studies, the present study has explored in some depth young people's attitudes towards and 'use' of rakhi relationships. Many students rejected the idea that girls and boys could only interact within officially sanctioned rakhi relationships, choosing instead to form heterosocial friendships. Students' preferences for certain heterosocial dynamics have also been considered within the context of wider cultural narratives. For example, the celebration of brother-sister relationships through Raksha Bandhan meant that rakhi relationships were tied to notions of Indian culture and national duty. However, this nationalistic trope was al so playfully undermined in popular and peer cultures, with rejection of a brother-sister relationship read as suggestive of romantic interest. Students often framed their own preferences for heterosocial friendships in terms of a rejection of traditional, conservative values. Friendships were associated with more modern social patterns, with boys and girls on a more equal footing (unlike the protector/protected binary of rakhi relationships), which allowed greater emotional closeness within platonic relationships, and also left open romantic possibilities. While not explored in detail within the present study, gender dynamics within heterosocial friendships in India form a compelling area for further research. Practices of gender segregation in Indian schools contribute to an overwhelming sense of gender difference (Kumar 1986), while institutional and peer cultures within schools often reinforce regressive gender narratives (Iyer 2017; Nayak and Kehily 2008). Forming heterosocial friendships, as opposed to rakhi relationships, could therefore be an important way in which young people can challenge and reject norms which emphasise gender difference and inequalities.

There are important issues relating to caste which have not been explored in this paper; for example, the ways in which students anticipated clashes between their present (sometimes inter-caste) romantic relationships, and future (almost inevitably intra-caste) marriages (Fuller and Narasimhan 2008; Donner 2008; Mody 2006). While it was beyond the scope of this paper to explore these issues in detail, findings discussed here do point to important class distinctions in terms of young people's ability to 'choose' between practices associated with tradition and modernity. While the urban, middle-class young people who participated in my study could re-negotiate and play with rakhi relationships, Chowdhry (2007) has discussed the more violent connotations of rakhi-tying for disadvantaged young people in rural North India, where inter-caste marriages are annulled by forcing couples to acknowledge each other as brother and sister. The fluidity of the boundaries between rakhi relationships and less platonic relationships is arguably enjoyed those of higher class status, such as the middle-class young people who participated in the present study. Others have noted that negotiating tradition and modernity can often be a fraught process for the urban middle classes (Gilbertson 2014; Phadke, Khan and Ranade 2011), but the ability to carry out these negotiations with some freedom are themselves a marker of class privilege.

Findings on coaching centre romances add a new dimension to existing literature on the importance of education to middle-class families in India; it would seem that these 'definers of middleclassness' (Kumar 2011, 238) also offer students the chance to interact with girls and boys outside school, and beyond the restrictive gaze of their parents and teachers. As 
well as sites of heightened academic pressure, coaching centres also act as new spaces for peer cultures to develop, and offer opportunities for romance and release.

Sexual activity among student couples was the exception rather than the norm; at least according to the students who participated in the present study; appropriate levels of intimacy within girlfriend-boyfriend relationships did not extend beyond hugging and kissing. Although stories of sexual encounters were told, the 'timepass' or casual sexual relationships discussed by Abraham's (2002) participants were not referred to by the young people who participated in this study, which may reflect their younger age bracket; in Abraham's (2002) study, casual sexual relationships were largely discussed by participants over the age of 18 . On the whole, the romantic relationships mostly highly valued in peer cultures within the present study were characterised by emotional attachment, with limited physical intimacy involved comparable to the 'true love' relationships described by Abraham (2002) and Gilbertson (2014).

Stories of couples who sought out spaces for any kind of physical intimacy were therefore filled with a sense of social risk. Such activity clearly contravened norms of gender segregation within the schools, and the disciplinary mechanisms specifically aimed at preventing such liaisons. However, many students were clearly willing to take these risks, which suggests that through peer romance, students were able to explore experiences of pleasure and intimacy which were side-lined within institutional risk-based narratives of sexuality. As discussed in lyer (2017), the gender dynamics within romantic courtship practices were not necessarily progressive. Nevertheless, by undermining norms of gender segregation and rakhi relationships, students seemed to reject 'Indian' cultural practices which they viewed as restrictive, and by pursuing heterosocial friendships and romantic relationships, instead aligned themselves with 'Western' sensibilities which many viewed more favourably. At the same time, as they circulated within peer cultures, stories of romantic relationships offered students an alternative source of sexual learning, in which risk-taking was viewed as exciting rather than life-threatening, and young people's exploration of their sexuality celebrated rather than condemned.

Acknowledgements: I would like to thank the Economicand Social Research Council (ESRC) for funding the research discussed in this paper. I would also like to thank my doctoral supervisors, Professor Janet Boddy, Professor Maya Unnithan and Rachel Thomson, for their extensive feedback on earlier versions of this work in my thesis; and the reviewers for their valuable suggestions for improvements to the paper during peer review. Most importantly, I would like to thank all the students, teachers in principal in Delhi who were involved in the study, for being so generous with their time and participation in the research. 


\section{References}

Abraham, L. 2002. "Bhai-Behen, True Love, Time-Pass: Friendships and Sexual Partnerships among Youth in an Indian Metropolis". Culture, Health and Sexuality 4 (3): 337-353.

Alldred, P. and M. E. David. 2007. Get Real About Sex: The Politics and Practice of Sex Education. Maidenhead: Open University Press.

Andrews, M. 2014. Narrative Imagination and Everyday Life. Oxford: Oxford University Press.

Bénéï, V. 2008. Schooling Passions: Nation, History and Language in Contemporary Western India. Stanford: Stanford University Press.

Chakraborty, K. 2010. "Unmarried Muslim Youth and Sex Education in the Bustees of Kolkata". South Asian History and Culture 1 (2): 268-281.

Chowdhry, P. 2007. Contentious Marriages, Eloping Couples: Gender, Caste and Patriarchy in Northern India. Oxford: Oxford University Press.

Connell, R. W. 2000. The Men and the Boys. Cambridge: Polity Press.

Dasgupta, R. 2014. Capital: A Portrait of Twenty-First Century Delhi. Noida: HarperCollins Publishers.

Doniger, W. 2011. "From Kama to Karma: The Resurgence of Puritanism in Contemporary India". Social Research 78 (1): 49-74.

Donner, H. 2008. Domestic Goddesses: Maternity, Globalisation and Middle-Class Identity in Contemporary India. Aldershot: Ashgate Publishing.

Donner, H. and G. De Neve. 2011. "Introduction". In Being Middle-Class in India: A Way of Life, edited by H. Donner, 1-22. Abingdon: Routledge.

Epstein, D. and R. Johnson. 1998. Schooling Sexualities. Buckingham: Open University Press.

Fuller, C. J. and H. Narasimhan. 2008. "Companionate Marriage in India: The Changing Marriage System in a Middle-Class Brahman Sub-Caste". The Journal of the Royal Anthropological Institute 14(4): 736-754.

Gilbertson, A. 2014. "A Fine Balance: Negotiating Fashion and Respectable Femininity in Middle-Class Hyderabad, India". Modern Asian Studies 48 (1): 120-158.

Iyer, P. 2017. “'Due To All This Fear, We're Getting Less Freedom': Young People's Understandings of Gender and Sexual Violence in New Delhi, India'. Gender and Education, DOI: 10.1080/09540253.2017.1306029.

Kehily, M. J. 2012. "Contextualising the Sexualisation of Girls Debate: Innocence, Experience and Young Female Sexuality". Gender and Education 24 (3): 255-268.

Kehily, M. and A. Nayak. 1996. "The Christmas Kiss: Sexuality, Storytelling and Schooling". Curriculum Studies 4 (2): 211-227.

Kumar, K. 1986. "Growing Up Male". Seminar 318 (1): 53-55.

Kumar, N. 2011. "The Middle-Class Child: Ruminations on Failure". In Elite and Everyman: The Cultural Politics of the Indian Middle Classes, edited by A. Baviskar and R. Ray, 220245. New Delhi: Routledge India.

Liechty, M. 2003. Suitably Modern: Making Middle-Class Culture in a New Consumer Society. Princeton: Princeton University Press.

Lukose, R. A. 2009. Liberalisation's Children - Gender, Youth and Consumer Citizenship in Globalising India. London: Duke University Press.

Nayak, A. and M. J. Kehily. 2008. Gender, Youth and Culture: Young Masculinities and Femininities. Basingstoke: Palgrave.

Nijman, J. 2006. "Mumbai's Mysterious Middle Class". International Journal of Urban and Regional Research 30 (4): 758-75.

Mehra, S., R. Savithri, and L. Coutinho. 2002. Sexual Behaviour among Unmarried Adolescents in Delhi, India: Opportunities Despite Parental Controls. New Delhi: MAMTA-Health Institute for Mother and Child. 
Mody, P. 2006. "Kidnapping, Elopement and Abduction: An Ethnography of Love-Marriage Delhi". In Love in South Asia: A Cultural History, edited by in F. Orsini, 331-344. Cambridge: Cambridge University Press.

Osella, C. and F. Osella. 2006. Men and Masculinities in South India. London: Anthem Press.

Parry, J. P. 2001. "Ankalu's Errant Wife: Sex, Marriage and Industry in Contemporary Chhattisgarh". Modern Asian Studies 35 (4): 783-820.

Phadke, S., P. Khan, and S. Ranade. 2011. Why Loiter? Women and Risk on Mumbai Streets. Gurgaon: Penguin India.

Plummer, K. 1995. Telling Sexual Stories: Power, Change and Social Worlds. London: Routledge.

Sancho, D. 2012. "The Year That Can Make or Break You: The Politics of Secondary Schooling, Youth and Class in Urban Kerala, South India". PhD diss., University of Sussex.

Sinha-Kerkhoff, K. 2003. "Practising Raksha Bandhan: Brothers in Ranchi, Jharkhand". Indian Journal of Gender Studies 10 (3): 431-455.

Srivastava, S. 2007. Passionate Modernity: Sexuality, Class and Consumption in India. New Delhi: Routledge.

Subiaya, L. 2008. "Premarital Sex in India: Issues of Class and Gender". Economic and Political Weekly 43 (48): 54-59.

Twamley, K. 2013. "Love and Desire among Middle-Class Gujarati Indians in the UK and India". Culture, Health and Sexuality 15 (3): 327-340.

Uberoi, P. 2011. "The Sexual Character of the Indian Middle Class: Sex Surveys, Past and Present". In Elite and Everyman: The Cultural Politics of the Indian Middle Classes, edited by A. Baviskar and R. Ray, 271-299. New Delhi: Routledge India.

van Wessel, M. 2011. "Cultural Contractions and Intergenerational Relations: The Construction of Selfhood among Middle-Class Youth in Baroda". In Being Middle-Class in India: A Way of Life, edited by H. Donner, 100-116. Abingdon: Routledge. 